\title{
Roles of Biomarkers in Myocardial Fibrosis
}

\author{
Yuejia Ding1, Yuan Wang', Wanqin Zhang1, Qiujin Jia ${ }^{1}$, Xiaoling Wang ${ }^{3}$, Yanyang Li $^{4}$, Shichao \\ Lv $^{1,2 *}$, Junping Zhang ${ }^{\text {* }}$
}

${ }^{1}$ First Teaching Hospital of Tianjin University of Traditional Chinese Medicine, Tianjin 300193, China

${ }^{2}$ Tianjin Key Laboratory of Traditional Research of TCM Prescription and Syndrome, Tianjin 300000, China

${ }^{3}$ Qian'an Hospital of Traditional Chinese Medicine, Qian'an 064400, China

${ }^{4}$ Tianjin Medical University Cancer Institute and Hospital, Tianjin 300060, China

[Received February 24, 2020; Revised June 3, 2020; Accepted June 4, 2020]

\begin{abstract}
Myocardial fibrosis is observed in various cardiovascular diseases and plays a key role in the impairment of cardiac function. Endomyocardial biopsy, as the gold standard for the diagnosis of myocardial fibrosis, has limitations in terms of clinical application. Therefore, biomarkers have been recommended for noninvasive assessment of myocardial fibrosis. This review discusses the role of biomarkers in myocardial fibrosis from the perspective of collagen.
\end{abstract}

Key words: biomarkers, collagen, myocardial fibrosis, review

\section{Introduction}

Myocardial fibrosis is characterized by alterations of the extracellular matrix and is an integral part of most cardiac pathological conditions [1]. Currently, five types of collagen are known to be expressed in the myocardium. The cardiac extracellular matrix is primarily composed of fibrillar collagen type I $(85 \%)$ and type III $(11 \%)$ [2, 3]. Small amounts of collagen type IV and V are found in the basement membrane of myocytes and in the pericellular space $[4,5]$. Besides, fibrillar collagen type VI is related to the adhesion of cellular fibers [6]. Extracellular collagen not only maintains cardiac fiber alignment, but also influences ventricle stiffness [7]. Moreover, an imbalance in collagen synthesis, breakdown, and metabolism accounts for the occurrence and development of myocardial fibrosis. Endomyocardial biopsy is undoubtedly the gold standard for the diagnosis of myocardial fibrosis, but it has limitations in clinical application. Therefore, biomarkers should be considered as a noninvasive method for detecting fibrosis. Myocardial fibrosis biomarkers have been investigated extensively, and fibrosis markers play an important role in the prognosis of cardiovascular diseases, such as heart failure (HF), dilated cardiomyopathy (DCM), and hypertrophic cardiomyopathy (HCM). This review summarizes the biomarkers of myocardial fibrosis from four collagen-related perspectives: synthesis, breakdown, metabolism, and gene transcription (miRNA).

\section{Collagen Synthesis}

\subsection{C-Terminal Propeptide of Procollagen Type I}

*Correspondence should be addressed to: Dr. Shichao Lv (email: 372272027@qq.com) and Junping Zhang (email: tjzhtcm@163.com), First Teaching Hospital of Tianjin University of Traditional Chinese Medicine, Tianjin 300193, China.

Copyright: (C) 2020 Ding Y et al. This is an open-access article distributed under the terms of the Creative Commons Attribution License, which permits unrestricted use, distribution, and reproduction in any medium, provided the original author and source are credited. 
Type I collagen is a heterotrimeric molecule, which is composed of two $\alpha 1$ chains and one $\alpha 2$ chain. During its synthesis, the protein undergoes a series of posttranslational modifications to form the procollagen chain; this precursor is then secreted into the extracellular space and cleaved by specific proteinases [8]. The stoichiometric ratio of the C-terminal propeptide of procollagen type I (PICP), which is released into the blood, and collagen type I produced by cleavage is 1:1 [9]. The heart secretes PICP into the peripheral circulation through the coronary sinus [9]. However, whether there is a positive correlation between plasma PICP, and myocardial collagen content remains controversial. A cross-sectional study demonstrated that plasma PICP levels in HCM patients were positively correlated with myocardial PICP content and the histological myocardial collagen volume fraction [10]. Similarly, Ferreira et al. also confirmed that the serum levels of PICP were significantly higher in patients with hypertension before drug treatment [11]. In contrast, in heart failure rats, Adamcova et al. observed that collagen content in the left ventricle was increased, whereas plasma PICP levels were reduced by $42 \%$ as compared to the control group [12]. These findings suggest that the myocardial collagen content does not necessarily correlate with plasma PICP, which may be related to confounding factors (such as weight loss and catabolic state). For predictive value, Ruiz-Ruiz et al. considered that serum PICP can be used independently for predicting HF episodes, hospital readmission, and death [13]. They included 111 patients with decompensated HF and found that $22.52 \%$ of the patients died during the 21 months of follow-up, and $48.6 \%$ of the patients were readmitted for HF. Moreover, serum PICP levels were significantly increased among patients who reached some primary endpoints (new hospitalizations or death) during follow-up $(88.12 \pm 37.31$ $\mathrm{ng} / \mathrm{mL}$ vs $73.13 \pm 34.06 \mathrm{ng} / \mathrm{mL} ; \mathrm{p}=0.029)$, and a cut-off value of $124 \mathrm{ng} / \mathrm{mL}$ predicted prognosis most accurately. Unfortunately, they did not perform cardiac biopsies, which is considered the most reliable method for measuring myocardial fibrosis.

\subsection{Procollagen Type I N-Terminal Propeptide}

Excessive deposition of collagen type $\mathrm{I}$ is a feature of cardiac remodeling [14]. The procollagen type I Nterminal propeptide (PINP) originates from conversion of collagen type I, and is a marker for collagen type I synthesis [15]. N-terminal pro-peptides are removed by members of the ADAMTS family [16]. Compared with PICP, PINP has the disadvantage of delayed release [17]. At present, the relationship between PINP levels and fibrosis remains elusive. In a case-control study, Zile et al. observed that the baseline serum PINP levels in patients with HF were significantly higher than those in controls [18]. In rats with ischemic cardiomyopathy, Zhang et al. detected significant cardiac fibrosis by Masson staining 6 weeks after myocardial infarction (MI), and enzyme-linked immunosorbent assay (ELISA) results showed that the level of plasma PINP in the MI group was significantly increased as compared to that in the normal control group [19]. However, in a cross-sectional study in which serum PINP levels were measured by radioimmunoassay, no significant difference was revealed between HCM patients and healthy individuals [20]. As shown by the above studies, PINP has some limitations as a biomarker.

\subsection{Procollagen Type III Amino-Terminal Propeptide}

Collagen type III, whose fibers have a relatively small diameter, is synthesized by cardiac fibroblasts and is mainly responsible for myocardial elasticity [21, 22]. After the C-propeptides of fibrillar procollagen are cleaved by proteases, procollagen type III amino-terminal propeptide (PIIINP) is released into the blood via the lymphatics [17]. The N-propeptide is considered to play an important role in the regulation of primary fibril diameter [23]. Excellent storage and stability are the characteristics of PIIINP [24]. However, PIIINP is sometimes not completely separated from procollagen, which leads to the underestimation of type III collagen synthesis. In a prospective study of dilated cardiomyopathy, baseline serum PIIINP levels in patients with idiopathic or ischemic dilated cardiomyopathy were significantly higher than those in healthy controls, and serum PIIINP levels were highly correlated with cardiac collagen type III levels [25]. Patients with a serum PIIINP value $>7 \mathrm{pg} / \mathrm{L}$ had a higher risk of a poor hemodynamic condition, advanced clinical stage, heart transplantation, hyponatremia, and death during follow-up than did patients with low PIIINP values [25]. This shows that the increase in serum PIIINP levels could reflect cardiac fibrosis to some extent, which was of prognostic value and was related to clinical stage. Additionally, PIIINP levels were positively correlated with diastolic dysfunction in patients with HF with reduced ejection fraction (HFrEF) [26], with left ventricular mass index (LVMI), and with relative wall thickness (RWT) in patients with successfully repaired coarctation of the aorta $(\mathrm{CoA})$ with left ventricular hypertrophy [27]. It was also inversely associated with diastolic function in patients with hypertension [28]. Moreover, in myocardial infarction (MI) model rats, the reduction in fibrosis with tanshinone IIA was accompanied by a reduction in serum PIIINP [29]. Taken together, PIIINP can reflect the degree of myocardial fibrosis. 


\section{Collagen Breakdown}

\subsection{C-Terminal Telopeptide of Collagen Type I}

During degradation of collagen type I fibrils, the Cterminal telopeptide of collagen type I (CITP) is a crosslinked terminal peptide released in a 1:1 stoichiometric ratio, allowing accurate measurement of collagen degradation [30, 31]. In a cross-sectional study, serum CITP levels in HCM patients were increased, while the PICP and PINP levels were not altered significantly, indicating a shift in the collagen balance toward collagen type I breakdown [20]. This is an important outcome, because increased myocardial stiffness is usually caused by collagen deposition. However, several other studies have shown that the relationship between CITP and myocardial fibrosis is controversial. In patients with HF and atrial fibrillation (AF), serum CITP levels were significantly higher than those in the control groups [32, 33]. But Nagao et al. observed that serum CITP levels in patients with DCM were not associated with left ventricular remodeling parameters, or with the expression of cardiac collagen type I and type III [34]. In addition, some studies have confirmed the predictive value of CITP. Manhenke et al. considered that plasma CITP was an independent predictor of cardiovascular mortality in patients with acute myocardial infarction (AMI) [35]. This prospective study included 233 patients with AMI, among whom $56 \%$ reached the combined endpoint of HF symptoms or $\mathrm{CV}$ death during the years of follow-up, and plasma ICTP was increased in patients who died due to any cause. Similarly, serum CITP is also useful for determining cardiac events in patients with complete HF [36]. In summary, CITP may facilitate diagnosis or prognosis of myocardial fibrosis.

\subsection{Matrix metalloproteinases}

Matrix metalloproteinases (MMPs) are zinc- and calciumdependent peptide enzymes that are involved in myocardial remodeling and degradation of collagen [37, 38]. It promotes the degradation of extracellular matrix, such as collagen, elastin, and gelatin [39]. MMPs can hydrolyze collagen efficiently, but their relative activities towards interstitial collagens are different. At $25^{\circ} \mathrm{C}$, MMP-1 preferentially cleaves collagen type III over types I and II [40]. MMP-13 cleaves collagen type II five-fold faster than collagen type I and six-fold more rapidly than collagen type III, at $25^{\circ} \mathrm{C}$ [41]. For MMP-2 and MMP-9, collagen type III is the substrate preferred over collagen types I and II [42, 43].

Many MMPs are expressed in the myocardium. In HCM, the expression of MMPs is altered, but not all MMPs are affected. Münch et al. found that MMP-1,
MMP-2, MMP-3, and MMP-9 are involved in HCM [44]. They observed that increased serum MMP-2 levels in females were associated with lower fibrosis, while MMP9 was positively associated with fibrosis in late gadolinium enhancement cardiac magnetic resonance (mean increase of 0.66 g/unit MMP-9 [0.50;0.82], p < 0.001), but neither serum MMP-1 nor MMP-3 levels were associated with cardiac fibrosis [44]. However, a cautionary note on these results is that the cardiac tissue concentration of MMPs was not evaluated, which might present a limitation. Regarding MMP-1 levels in systolic and diastolic HF, serum MMP-1 levels were increased in systolic HF patients, but not in diastolic HF patients [45, 46]. This result reminds us that MMP activity also fluctuates because heart remodeling during $\mathrm{HF}$ is a dynamic process. In diabetic mice (DM), myocardial fibrosis is clearly related to the expression of MMP7, MMP11, MMP13, and MMP16 in myocardial tissue [47]. Compared with the control group, levels of MMP7, MMP11, MMP13, and MMP16 were markedly higher, but levels of MMP2 were markedly lower in the DM group [47]. It is also important to note the measurement method of MMPs in all the above studies. The levels of different MMPs are determined by immunohistochemistry or histology or by enzyme-linked immunosorbent assays, but these methods do not distinguish proMMPs from active MMPs. Therefore, these results are of limited value.

\subsection{Tissue Inhibitors of Metalloproteinase}

Tissue inhibitors of metalloproteinase (TIMPs) are a group of low molecular weight glycoproteins. TIMPs are produced and secreted by fibroblasts, epithelial cells, and endothelial cells, and are distributed among tissues and humors [48]. TIMPs can promote the differentiation of fibroblasts into myofibroblasts at the site of tissue injury [49]. In addition, TIMPs control the proteolytic activity of MMPs [50]. Specifically, TIMPs can specifically bind to the zinc ions in the catalytic site of MMPs through the cysteine residues, thus disbanding activated MMPs, or preventing inactive MMPs from becoming activated [47]. Therefore, the balance between MMP and TIMP expression is essential for reconstruction of the extracellular matrix in myocardial tissues [51].

Currently, 4 types of TIMPs have been found to be associated with myocardial fibrosis. TIMP1 mediates the interaction between fibroblast membrane protein CD63 and integrin $\beta 1$, which is widely expressed in various cells, thus triggering fibrosis [52-55]. At the cellular level, hirudin reverses Ang II-induced fibrosis by elevating TIMP-2 expression [56]. TIMP3 is the only TIMP that can inhibit the activity of TNF- $\alpha$-converting enzyme and may have a protective effect against fibrosis by upregulating 
cytokines involved in myofibroblast activation and immunity [57]. In addition, Rizzi et al. investigated whether there was a correlation between cardiac TIMP-4 levels and cardiac hypertrophy in $2 \mathrm{~K} 1 \mathrm{C}$ hypertension rats [58]. They observed higher TIMP-4 levels $(325 \pm 68 \%)$ in hypertensive rats than in sham-operated animals at 75 days after $2 \mathrm{~K} 1 \mathrm{C}$ surgery. This result suggested that the increase in TIMP-4 activity was associated with concomitant development of cardiac hypertrophy. Another way to determine the severity of fibrosis is by measuring the MMP/TIMP ratio. Parkkonen et al. observed a large increase in serum TIMP-1 and MMP-2 levels in patients with takotsubo cardiomyopathy (TTC) compared with that in healthy controls, and proposed that the low MMP-8/TIMP-1 molar ratio may reflect increased transient fibrosis and decreased proteolysis [59]. This result indicates that the TIMP/MMP balance may play an important role in the development of myocardial fibrosis. In addition, the predicted value of TIMP-1 is also noteworthy. Frantz et al. investigated the association between TIMP-1 plasma levels and clinical endpoints (death due to any cause), and found that plasma TIMP-1 levels increased in HF patients as compared with healthy controls (1640 vs $735 \mathrm{ng} / \mathrm{mL}$, respectively,) [60]. Moreover, the researchers also observed that patients with high TIMP-1 levels (1917 ng/mL) had a significantly higher mortality rate than patients with lower levels (1390 $\mathrm{ng} / \mathrm{mL}$ ). These results suggest that an increase in TIMP-1 indicates a poor prognosis in HF patients.

The collagen synthesis and degradation processes are briefly described in Fig. 1.

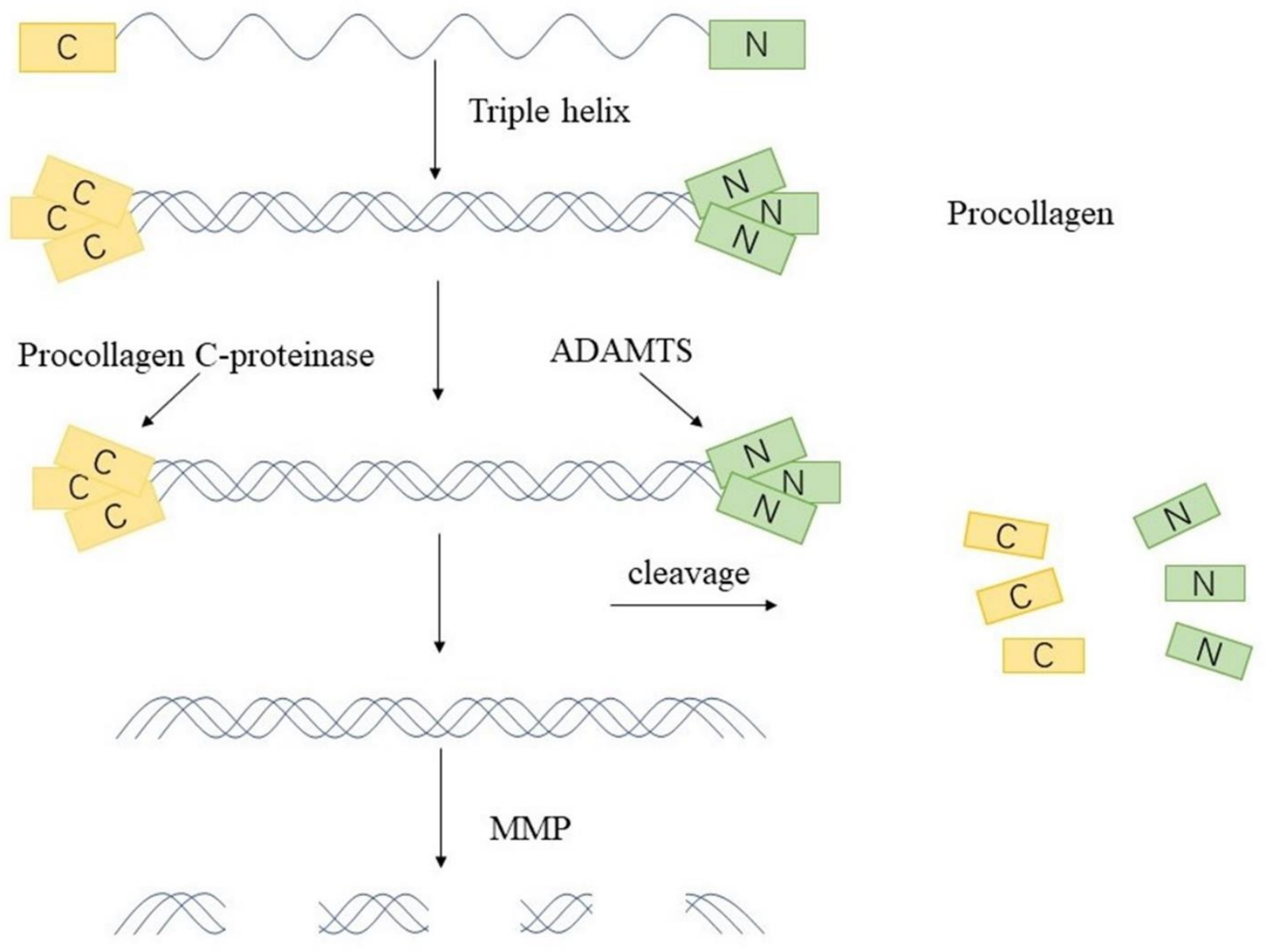

Degradation

Figure 1. The process of collagen synthesis and degradation. 


\section{Collagen Metabolism}

\subsection{Transforming Growth Factor- $\beta$ and Smads}

Transforming growth factor- $\beta$ (TGF- $\beta$ ) is a crucial profibrotic cytokine involved in myocardial fibrosis [61]. It is involved in the regulation of fibroblast proliferation, transformation, and migration, and production of the extracellular matrix [62]. As a cytokine upstream of LOX in cardiac fibroblasts, TGF- $\beta$ activates fibrosis via the Smad3, PI3K/Akt, and MAPK signaling pathways [63]. In addition, the heterodimeric cell surface receptor complex composed of type I TGF- $\beta$ receptors and type II TGF- $\beta$ receptors plays an important role in signal transduction of cardiac fibroblasts $[64,65]$.

In various animal models of heart disease, inhibition of the effect of TGF- $\beta$ successfully reduced or prevented the development of fibrosis. In MI mice, anti-TGF- $\beta$ treatment after coronary artery ligation increased the expression of MMPs and decreased the production of collagen [66]. Similarly, in pressure-overloaded rats, the delivery of anti-TGF- $\beta$ neutralizing antibody inhibited the activation of fibroblasts and prevented the induction of collagen type I and type III mRNA [67]. These observations indicated that anti-TGF treatment prevented excessive extracellular matrix deposition. Moreover, Koitabashi et al. observed that deletion of the TGF- $\beta$ type II receptor (T $\beta R 2)$ gene in cardiomyocytes inhibited cardiac hypertrophy, and that transverse aortic constriction (TAC) mice receiving anti-TGF agents displayed significantly suppressed perivascular and interstitial fibrosis [68]. Taken together, these data emphasize the key role of TGF- $\beta$ in cardiac fibrosis.

Smads, as key intracellular effectors of the TGF- $\beta 1$ class, and play a central role in cardiac remodeling [69, 70]. Research has suggested that the up-regulatory effect of TGF- $\beta 3$ on the migration, proliferation, and collagen synthesis of human cardiac fibroblasts may be attributed to the action of Smad7 [71]. Khalil et al. found that the absence of Smad3, Smad2/3, or Tgfbr1/2 markedly attenuated cardiac fibrosis after 12 weeks of TAC stimulation in rats [72]. In Smad3-deficient mice, the collagen content in the infarcted hearts decreased at 7 days after reperfusion, and collagen deposition in the uninfarcted, remodeling myocardium was markedly attenuated [73]. These findings suggest that Smad gene disruption leads to attenuation of the remodeling process. 4.2 Connective Tissue Growth Factor

Connective tissue growth factor (CTGF) belongs to the $\mathrm{CCN}$ family of multifunctional matricellular proteins, and it is involved in the process of triggering fibrosis in multiple organs and tissues, including the heart $[74,75]$. Many in vitro studies have demonstrated that CTGF promotes the differentiation of fibroblasts into myofibroblasts and enhances extracellular matrix production [76-78]. CTGF is also a critical mediator of the downstream signaling of the profibrotic cytokine TGF- $\beta$ $[79,80]$. In DCM model rats, CTGF/CCN2 gene silencing improved cardiac function, attenuated myocardial fibrosis, and left ventricular hypertrophy [81]. In an in vitro study, $\beta$-adrenergic receptor overstimulation could induce the synthesis and secretion of CTGF in cardiomyocytes, thereby affecting the activation of cardiac fibroblasts [82]. Dean et al. observed the expression of spatiotemporal CTGF during the development of myocardial fibrosis in experimental MI rats [83]. They confirmed that the expression of CTGF protein and mRNA was upregulated rapidly in the infarcted region within a few days after MI [83]. These findings suggest that CTGF plays a key role in myocardial fibrosis. Furthermore, Koitabashi et al. proposed that plasma CTGF could be used as a diagnostic marker for chronic HF [84]. They found that plasma CTGF levels in symptomatic choric HF patients were significantly increased in proportion to their NYHA classes and were correlated with plasma BNP concentration $(r=0.395$, $\mathrm{P}<0.01)$. However, they did not measure the concentration of CTGF in aortic root blood and coronary sinus blood; thus, the source of CTGF production is unknown. In brief, CTGF may be a predictor of myocardial fibrosis.

\subsection{Corin}

Corin is a transmembrane protease that is mainly expressed in cardiomyocytes [85]. It is closely correlated with natriuretic peptides that regulate many signaling functions, such as cGMP levels, vasodilation, natriuresis, fibrosis, etc. [86, 87]. In DCM model mice, increasing the expression of cardiac corin not only reduced fibrosis and HF, but also increased survival [88]. This finding indicates that corin correlates with the prognosis of DCM. In a cross-sectional study, plasma corin levels were lower in $\mathrm{HF}$ patients $(365 \mathrm{pg} / \mathrm{mL}[ \pm \mathrm{SD}, 259 \mathrm{pg} / \mathrm{mL}] ; \mathrm{P}<0.001)$ than in healthy controls, and this reduction was closely related to the severity of the disease $(\mathrm{P}<0.001$ for NYHA class II vs. class IV; P $<0.05$ for NYHA class III vs. class IV) [85]. The results demonstrated that plasma corin may indicate pathological conditions in the heart. In canines with HF, the staining intensity of collagen was markedly elevated, while the expression of corin mRNA and protein was lower than that in the control group [89]. Contrary to these findings, Tran et al. observed upregulation of corin gene expression in the failing myocardium and in hypertrophic cardiomyocytes [90]. These studies suggest that the expression of corin may differ according to the disease state. In summary, corin may be an attractive diagnostic and prognostic biomarker of myocardial fibrosis. 


\subsection{Mesenchymal cell products}

Recently, endothelial-to-mesenchymal transition (EndoMT) has been considered as a potential mechanism in pathological fibrosis. In the complex biological process of EndoMT, endothelial cells lose their specific cellular markers, and then acquire a mesenchymal or myofibroblast phenotype to initiate expression of mesenchymal cell products, such as $\alpha$-smooth muscle actin $(\alpha-S M A)$, vimentin, and fibronectin [91]. In a rat model of isoproterenol (ISO) -induced myocardial fibrosis, cardiac $\alpha$-SMA and vimentin levels increased, peaking on day 3 , and then gradually decreased [92]. This result suggests that $\alpha$-SMA and vimentin activity fluctuates in the fibrosis process. $\alpha$-SMA, fibronectin, and vimentin are also involved in the process of diabetic cardiomyopathy [93]. The immunohistochemistry data showed that diabetes enhanced the expression of cardiac $\alpha$-SMA, fibronectin, and vimentin compared with normal rats. Moreover, in vitro treatment of mouse embryonic fibroblasts with WF-A reduced the stability of collagen mRNA, but in the absence of vimentin, WF-A did not change the half-life of collagen mRNAs [94]. We therefore conclude that vimentin filaments play a crucial role in collagen expression. In short, $\alpha$-SMA, vimentin, and fibronectin might be essential elements in cardiac fibrosis.

\subsection{Inflammatory Factors}

Inflammation caused by infection and tissue necrosis is a physiological response that promotes tissue healing through fibrosis, but it may become excessive when accompanied by additional factors, such as mechanical stress, genetic background, activation of neurohumoral factors, oxidative stress, and autoimmunity, causing pathological remodeling through Gal-3, TNF- $\alpha$, interleukin, MMPs, miRNA activation, and other mechanisms.

Galectin-3 (Gal-3), a $\beta$-galactoside-binding lectin, plays a regulatory role in fibrogenesis. It is widely expressed by various types of inflammatory cells, binds to extracellular glycoproteins, and activates fibroblasts to increase collagen I deposition [95-97]. Growing evidence indicates that high levels of circulating Gal-3 are associated with an increased risk of adverse cardiovascular events, such as HF, myocardial infarction, dilated cardiomyopathy, and fibrogenesis [98-101]. In mice with ischemia/reperfusion (I/R) injury, there was a two-fold increase in plasma Gal-3 levels, and in the ischemic myocardium, Gal-3 was upregulated seven-fold at the mRNA level and 30-fold at the protein level [102]. In addition, that study revealed that plasma Gal-3 concentrations were always higher in DCM/ICM patients with HF than in non-HF subjects, but no trans-cardiac or trans-hepatic concentration gradient of Gal-3 was found. The aforementioned studies were limited in that they did not obtain myocardial biopsies to measure cardiac Gal-3 expression. Moreover, serum Gal-3 is considered to be associated with inflammation and cardiovascular fibrosis. In patients with AMI, serum Gal-3 levels increased immediately after AMI and then declined significantly within 5 days [103]. These data indicate that Gal-3 is closely related to the formation, destabilization, and rupture of plaque. Besides observational studies of Gal-3 levels, several studies have investigated the predictive value of Gal-3. Van Kimmenade et al. observed that an increased circulating Gal-3 level was the best independent predictor of 60-day mortality (odds ratio 10.3, P < 0.01) in patients with acute HF [104]. In patients with coronary artery disease (CAD), Maiolino et al. found that patients with Gal-3 levels in the highest tertile were more prone to death due to cardiovascular causes $(25.2 \%)$ than those with Gal-3 levels in the intermediate and lower tertiles (13.6\% and $7.5 \%$, respectively; $\mathrm{P}<0.001)$, and the plasma Gal-3 cutoff value for cardiovascular death prediction was $27.7 \mathrm{ng} / \mathrm{mL}$ [105]. Unfortunately, the loss of $25 \%$ of the patients to follow-up may have limited the results of the study. Overall, these findings confirm that elevated Gal-3 is associated with cardiovascular disease progression and poor outcome.

A growing body of evidence has demonstrated that macrophages and monocytes not only play a key role in the occurrence and development of fibrotic responses, but may also mediate the regression of fibrosis [106]. Macrophages and monocytes are capable of producing and excreting a large number of pro-inflammatory mediators, such as tumor necrosis factor- $\alpha$ (TNF- $\alpha$ ), interleukin-1 $\beta$ (IL-1 $\beta$ ), IL-4, and IL-6 [107]. Furthermore, a complex regulatory network consisting of these inflammatory factors activates both myofibroblasts and fibrotic pathological processes [107]. This was supported by Kang et al., who treated primary cardiomyocytes with $35 \mathrm{mmol} / \mathrm{L}$ glucose for $24 \mathrm{~h}$ [108]. The ELISA results showed that the levels of TNF- $\alpha$, IL- 6 , and IL- $1 \beta$ and the expression of collagen I and III mRNA were higher than those in the normal control group [108]. These findings suggest that fibrosis is associated with inflammation. In a cross-sectional study of HCM, Fang et al. observed that plasma IL-4, IL-6, and IL-10 levels were positively correlated with diffuse and regional myocardial fibrosis [97]. Unfortunately, owing to the cross-sectional nature of the research, it is impossible to determine whether this association was causal. In addition, in order to study the role of IL-11 signal transduction in cardiovascular fibrosis, Schafer et al. generated IL-11 knockout mice. Compared with wild-type mice, they observed less cardiac fibrosis in knockout mice after either transverse 
aortic constriction or AngII infusion, suggesting that IL11 inflammatory factors are involved in the pathological is a crucial profibrotic gene [109]. In summary, process of myocardial fibrosis.

Table 1. Biomarkers of myocardial fibrosis (collagen synthesis, breakdown, metabolism).

\begin{tabular}{|c|c|c|c|c|}
\hline Biomarkers & Studied Condition & Test Location & Main findings & Reference \\
\hline \multirow{3}{*}{ PICP } & HCM patients & Plasma & $\mathrm{PICP} \uparrow$ & {$[10]$} \\
\hline & Hypertension patients & Serum & $\mathrm{PICP} \uparrow$ & {$[11]$} \\
\hline & $\mathrm{HF}$ rats & Plasma & $\mathrm{PICP} \downarrow$ & {$[12]$} \\
\hline \multirow{5}{*}{ PINP } & HF patients & Serum & $\mathrm{PICP} \uparrow$ & [13] \\
\hline & HFrEF patients & Serum & $\mathrm{PINP} \uparrow$ & {$[18]$} \\
\hline & MI rats & Plasma & $\mathrm{PINP} \uparrow$ & [19] \\
\hline & HCM patients & Serum & Not predictive in fibrosis & [20] \\
\hline & DCM patients & Serum & PIIINP $\uparrow$ & {$[25]$} \\
\hline \multirow{3}{*}{ PIIINP } & HFrEF patients & Serum & $\begin{array}{l}\text { PIIINP } \uparrow \text {, positively associated with diastolic } \\
\text { function }\end{array}$ & {$[26]$} \\
\hline & CoA patients & Serum & $\begin{array}{l}\text { PIIINP } \uparrow \text {, positively associated with LVMI and } \\
\text { RWT }\end{array}$ & {$[27]$} \\
\hline & Hypertension patients & Serum & $\begin{array}{l}\text { PIIINP } \uparrow, \text { inversely associated with diastolic } \\
\text { functions }\end{array}$ & {$[28]$} \\
\hline \multirow{5}{*}{ CITP } & MI rats & Serum & PIIINP $\uparrow$ & {$[29]$} \\
\hline & HF patients & Serum & $\mathrm{CITP} \uparrow$ & [20] \\
\hline & $\mathrm{HF}$ and $\mathrm{AF}$ patients & Serum & CITP $\uparrow$ & [32-33] \\
\hline & DCM patients & Serum & Not predictive in fibrosis & [34] \\
\hline & AMI patients & Serum & CITP $\uparrow$, predicts cardiovascular mortality & [35] \\
\hline \multirow{3}{*}{ MMPs } & HCM patients & Serum & $\begin{array}{l}\text { MMP-2 } \downarrow \text {, MMP-9 was positively associated with } \\
\text { fibrosis }\end{array}$ & [44] \\
\hline & systolic HF patients & Serum & MMP-1 $\uparrow$ & {$[45-46]$} \\
\hline & DM rats & Myocardial tissues & MMP2 $\downarrow$, MMP7, MMP11, MMP13, MMP16个 & [47] \\
\hline \multirow{3}{*}{ TIMPs } & $\begin{array}{l}2 \mathrm{~K} 1 \mathrm{C} \text { hypertension } \\
\text { rats }\end{array}$ & Myocardial tissues & TIMP-4 $\uparrow$ & {$[58]$} \\
\hline & TTC patients & Serum & TIMP-1 and MMP-2 $\uparrow$ & [59] \\
\hline & HF patients & Serum & TIMP-1 $\uparrow$ & {$[60]$} \\
\hline \multirow{3}{*}{ TGF- $\beta$} & MI mice & Myocardial tissues & $\begin{array}{l}\text { anti-TGF- } \beta \text { treated: collagen production } \downarrow \text {, } \\
\text { matrix-metalloproteinase } \uparrow\end{array}$ & {$[66]$} \\
\hline & Pressure-overload rats & Myocardial tissues & $\begin{array}{l}\text { anti-TGF- } \beta \text { treated: fibroblast activation } \downarrow \text {, } \\
\text { collagen mRNA induction } \downarrow\end{array}$ & [67] \\
\hline & TAC mice & Myocardial tissues & $\begin{array}{l}\text { anti-TGF- } \beta \text { treated: perivascular and interstitial } \\
\text { fibrosis } \downarrow\end{array}$ & {$[68]$} \\
\hline \multirow{2}{*}{ Smads } & TAC mice & Cardiac tissues & Smad3 or Smad $2 / 3$ deletion: cardiac fibrosis $\downarrow$ & {$[72]$} \\
\hline & Smad3-deficient mice & Myocardial tissues & Collagen content and deposition $\downarrow$ & {$[73]$} \\
\hline \multirow{2}{*}{ CTGF } & DCM rats & Myocardial tissues & $\begin{array}{l}\text { CTGF/CCN2 gene silencing: cardiac function } \uparrow \text {, } \\
\text { myocardial fibrosis and left ventricular } \\
\text { hypertrophy } \downarrow\end{array}$ & [81] \\
\hline & MI rats & Myocardial tissues & $\mathrm{CTGF} \uparrow$ & {$[83]$} \\
\hline \multirow{4}{*}{ Corin } & Chronic HF patients & Plasma & $\mathrm{CTGF} \uparrow$ & [84] \\
\hline & HF patients & Plasma & Corin $\downarrow$ & {$[85]$} \\
\hline & HF canines & Myocardial tissues & Corin $\downarrow$ & [89] \\
\hline & HCM disease & Cardiomyocytes & Corin $\uparrow$ & [90] \\
\hline \multirow{3}{*}{ EndoMT } & ISO-induced fibrosis & Myocardial tissues & $\begin{array}{l}\alpha \text {-SMA and vimentin: } \uparrow \text { with a peak on day } 3 \text {, and } \\
\text { then gradually } \downarrow\end{array}$ & {$[92]$} \\
\hline & DCM rats & Myocardial tissues & a-SMA, fibronectin and vimentin $\uparrow$ & {$[93]$} \\
\hline & In vitro & $\begin{array}{l}\text { Mouse embryonic } \\
\text { fibroblasts }\end{array}$ & $\begin{array}{l}\text { Vimentin deletion: WF-A did not change half- } \\
\text { lives of collagen mRNAs }\end{array}$ & [94] \\
\hline Gal-3 & $\begin{array}{l}\text { Myocardial I/R injury } \\
\text { rats }\end{array}$ & Myocardial tissues & Gal-3 $\uparrow$ & [102] \\
\hline
\end{tabular}




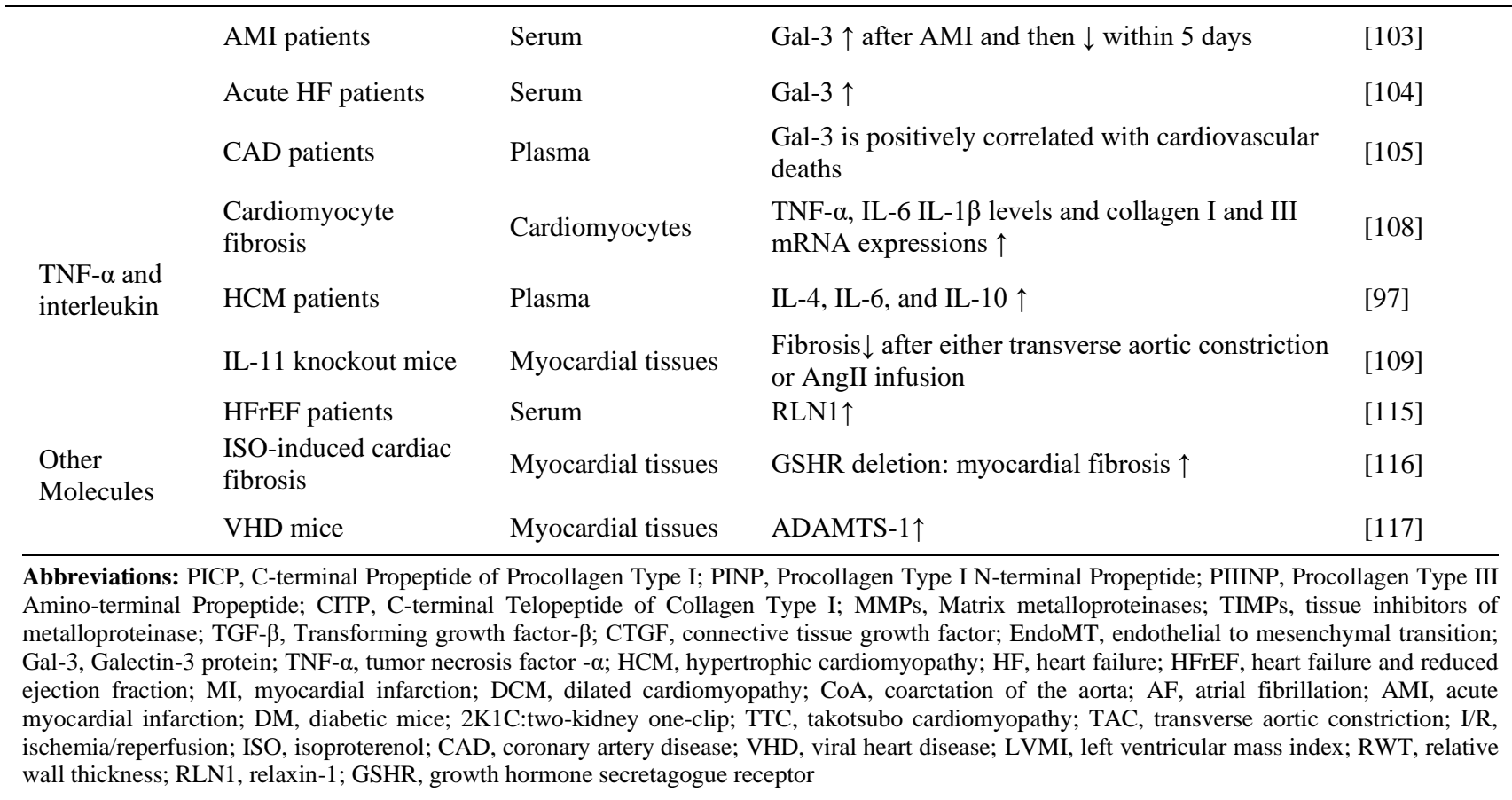

MMPs and miRNAs also play a regulatory role in the process of inflammatory fibrosis. Tissue injury induces activation of inflammatory mediators and recruitment of inflammatory cells. Inflammatory cells promote fibrosis by producing cytokines/chemokines that regulate MMPs [110]. MMP-9, the most widely documented protease in the inflammatory process, is involved in the initial stage of myocardial injury. The increase in MMP-9 levels is related to the invasion of necrotic tissue by inflammatory cells, particularly polymorphonuclear neutrophils and activated satellite cells [111]. Moreover, in the cardiovascular system, miRNAs control the expression of some inflammatory factors. For example, miR-155 controls the expression of SHIP1 and SOCS1, the key regulators of the inflammatory response in macrophages [112]. Elevated miR-21 expression in macrophages inhibited the production of TNF- $\alpha$ and the up-regulation of IL-10, respectively [113]. Overall, these inflammatory markers are associated with fibrosis.

4.6 Other Molecules

The development of myocardial fibrosis also involves factors such as relaxin-1 (RLN1), growth hormone secretagogue receptor (GSHR), ADAMTS-1, and transient receptor potential melastatin 7 (TRPM7). RLN, a polypeptide hormone, is secreted by cardiac cells [114]. In a cross-sectional study, the average circulating RLN1 levels in the HFrEF patient population were markedly higher than those in healthy control subjects $(702 \pm 283 \mathrm{pg} / \mathrm{mL}$ vs. $44 \pm 27 \mathrm{pg} / \mathrm{mL})$, with elevated RLN1 levels accompanied by a decrease in heart fibrosis [115]. This finding promotes the study of RLN1 as a potential anti-fibrosis target. GSHR is an orexigenic hormone with newly defined cardiovascular effects. In a mouse model of isoproterenol-induced myocardial fibrosis, GHSR deficiency exacerbated the expression of myofibroblast trans-differentiation marker genes, suggesting that GHSR may be a surrogate indicator of the need for intervention in myocardial fibrosis [116]. ADAMTS-1, a metalloprotease with proteolytic activity, also has the ability to cleave the N-terminal propeptide of collagen. In mice with viral heart disease (VHD), Li et al. observed that the collagen volume fraction increased significantly, accompanied by elevated expression of ADAMTS-1 mRNA in cardiac tissue ( $<$ 0.001) [117]. Moreover, TRPM7 is capable of promoting the proliferation and differentiation of fibroblasts and increasing the synthesis of extracellular matrix proteins [118].

In general, these molecules, which are closely related to collagen synthesis, breakdown, and metabolism, have recently been proposed as intervention targets for myocardial fibrosis (Table 1).

\section{Gene Transcription (miRNA)}

MicroRNAs (miRNAs) are small, noncoding RNAs that regulate gene expression after transcription, and play a critical role in heart function and pathology [119]. The miRNA family regulates gene expression by inducing target mRNA destabilization or inhibiting protein translation [120]. The marked cardiospecific capacity of 
some miRNAs is beneficial for ameliorating tissue remodeling.

The relationship between miR-21 and myocardial fibrosis has been extensively studied. miRNAs target not only single genes, but also overall networks that contribute to biological function. For example, in patients with aortic stenosis (AS), myocardial and plasmatic miR21 levels predicted collagen type I, collagen type III, and fibronectin expression by targeting RECK, PDCD4, and TGF- $\beta$-signaling factors [121]. In animal models of myocardial infarction, miR-21 promoted the transformation of cardiac fibroblasts (CFs) to myofibroblasts, and increased myocardial fibrosis in vivo by targeting Jagged1 [122]. In addition, the overexpression of miR-21 in allogeneic mice activated the fibrosis gene program and promoted the differentiation of monocytes to fibroblasts via the phosphatase and tensin homologue/activator protein 1 regulatory axis (PTEN/AP-1) [123]. Intriguingly, Szemraj-Rogucka et al., in a study of 13 left ventricular non-compaction patients (LVNC), found that plasma levels of miR-21, miR-29a, miR-30d, and miR-133a were both significantly elevated, suggesting that all four miRNAs may serve as biomarkers of myocardial fibrosis [124]. Unfortunately, this study was performed using a small sample size, which may have biased the results.

Table 2. Biomarkers of myocardial fibrosis (gene transcription).

\begin{tabular}{|c|c|c|c|c|}
\hline MiRNA & Study condition & Pathway & Main findings & Reference \\
\hline \multirow{4}{*}{$\operatorname{miR}-21$} & AS patients & $\begin{array}{l}\text { RECK, PDCD4, } \\
\text { and TGF- } \beta\end{array}$ & Predicts myocardial collagen expression & {$[121]$} \\
\hline & MI mice & Jagged 1 & $\begin{array}{l}\text { CFs-myofibroblasts transformation } \uparrow, \text { myocardial } \\
\text { fibrosis } \uparrow\end{array}$ & {$[122]$} \\
\hline & $\begin{array}{l}\text { Cardiac allograft } \\
\text { transplantation } \\
\text { model }\end{array}$ & $\begin{array}{l}\text { PTEN/AP-1 } \\
\text { pathway }\end{array}$ & $\begin{array}{l}\text { Fibrosis gene program } \uparrow, \text { monocytes-fibroblasts } \\
\text { transformation } \uparrow\end{array}$ & {$[123]$} \\
\hline & LVNC paitients & - & $\begin{array}{l}\text { Plasma miR-21, miR-29a, miR-30d and miR- } \\
\text { 133a } \uparrow\end{array}$ & [124] \\
\hline \multirow{2}{*}{$\operatorname{miR}-29$} & \multirow{2}{*}{$\begin{array}{l}\text { Pathological } \\
\text { hypertrophy model } \\
\text { Cardiac hypertrophy } \\
\text { mice }\end{array}$} & - & Cardiac miR-29a, mir-29c $\downarrow$ & {$[127]$} \\
\hline & & - & $\begin{array}{l}\text { Prevented Col1a1, Col1a2 and Col3a1 } \\
\text { expression }\end{array}$ & [128] \\
\hline $\operatorname{miR}-1$ & $\begin{array}{l}\text { Myocardial } \\
\text { hypertrophy model }\end{array}$ & FBLN2 & Cardiac remodeling $\downarrow$ & [129] \\
\hline $\operatorname{miR}-378$ & TAC rats & $\begin{array}{l}\text { Paracrine } \\
\text { mechanisms }\end{array}$ & Cardiac fibrosis $\downarrow$ & {$[130]$} \\
\hline $\operatorname{miR}-203$ & DCM rats & $\begin{array}{l}\text { PI3K/Akt } \\
\text { signaling } \\
\text { pathway }\end{array}$ & Prevented cardiac Col I, Col III expression & [131] \\
\hline miR-135a & $\begin{array}{l}\text { Cardiac hypertrophy } \\
\text { model }\end{array}$ & $\begin{array}{l}\text { TGF- } \beta / \text { Smads } \\
\text { pathway }\end{array}$ & Associated with the $\alpha$-SMA and Co I & [132] \\
\hline $\begin{array}{l}\text { miR-135a, miR- } \\
\text { 202-3p, miR-122, } \\
\text { miR-195 and miR- } \\
328\end{array}$ & Fibrosis model & $\begin{array}{l}\text { TGF } \beta 1 \text { signaling } \\
\text { pathway }\end{array}$ & $\begin{array}{l}\text { Involved in the progression and development of } \\
\text { myocardial fibrosis }\end{array}$ & {$[132-136]$} \\
\hline $\operatorname{miR}-197-5 \mathrm{P}$ & HF patients & - & $\begin{array}{l}\text { miR-197-5P } \uparrow \text {, associated with adverse cardiac } \\
\text { events }\end{array}$ & [138] \\
\hline miR-208, miR-499 & AMI paitients & - & $\begin{array}{l}\text { Mediates cardioblasts-cardiomyocytes } \\
\text { transformation and muscle fiber specification }\end{array}$ & [139] \\
\hline miR-101, miR-150 & MI rats & - & Cardiac miR-101 and miR-150 & [140-141] \\
\hline $\operatorname{miR}-144$ & MI model & - & $\begin{array}{l}\text { miR-144 deletion: cardiac collagen content } \uparrow \text {, } \\
\text { cardiac function } \downarrow\end{array}$ & [142] \\
\hline miR-101a & MI rats & - & $\begin{array}{l}\text { Intermittent aerobic exercise: cardiac miR-101a } \\
\uparrow\end{array}$ & [143] \\
\hline
\end{tabular}

Abbreviations: AS, aortic stenosis; MI, myocardial infarction; LVNC, left-ventricular non-compaction; TAC, transverse aortic constriction; DCM, dilated cardiomyopathy; I/R, ischemia/reperfusion; HF, heart failure; AMI, acute myocardial infarction; CFs, cardiac fibroblasts; FBLN2, Fibullin-2; PTEN/AP-1, phosphatase and tensin homologue/activator protein 1 regulatory; $\alpha$-SMA, $\alpha$-smooth muscle actin; TGF- $\beta$, Transforming growth factor- $\beta$ 

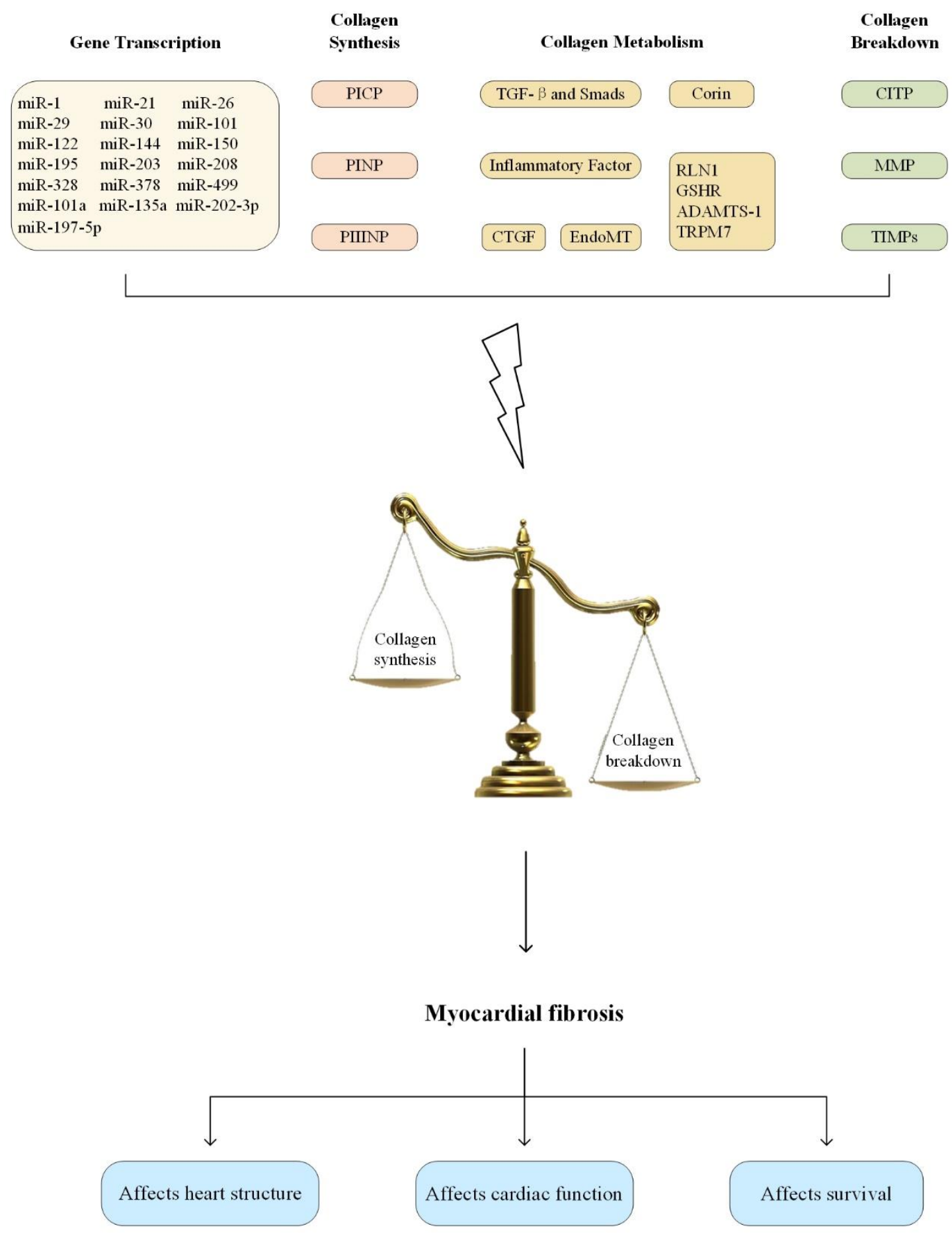

Figure 2. Biomarkers and pathological effects of myocardial fibrosis.

Another well-researched miRNA is miR-29, which demonstrates reduced expression under cardiac stress conditions, and thus may promote more extracellular matrix protein production by "derepression" of elastin, genes encoding collagens, and fibrillin [125]. Heid et al. found that overexpression of the miR-29 family counteracted the physiological accumulation of oxidative damage during aging, thereby protecting the heart against the detrimental effects of fibrosis [126]. In patients with pathological hypertrophy, TaqMan quantitative polymerase chain reaction showed a marked decrease in cardiac miR-29a and miR-29c, suggesting that miR-29 expression has been linked to extracellular matrix remodeling in cardiac hypertrophy [127]. MiR-29 is also 
a good example of a potential therapeutic target. For example, infusion of anti-miR-29 into cardiac hypertrophy model mice could prevent the expression of fibrosis markers, such as Col1a1, Col1a2, and Col3a1 [128]. Together, the miR-29 family plays a key role in pathological hypertrophy of the myocardium and fibrosis.

Other cardiomyocyte-associated miRNAs, such as miR-26, miR-30, miR-135, and miR-208, are also involved in cardiac fibrosis. miR-1 expression reverses pressure-induced myocardial hypertrophy and prevents cardiac remodeling by secretion of the protein fibullin-2 (FBLN2), which is related to extracellular matrix remodeling [129]. miR-378 is secreted from cardiomyocytes at the early stage of cardiac remodeling after mechanical stress and inhibits excessive cardiac fibrosis through paracrine mechanisms [130]. Overexpression of miR-203 prevented cardiac collagen type I and type III expression in DCM mice by targeting PIK3CA through inactivation of the PI3K/Akt signaling pathway [131]. As upstream molecules of TGF- $\beta$, miR135a, miR-122, miR-195, miR-202-3p, and miR-328 also participate in the process of fibrosis by regulating the expression of myocardial collagen [132-136]. Rubiś et al. found that baseline serum levels of miR-21, miR-26, miR29 , and miR-30 were significantly different in DCM patients than in controls, and that MMP-2 levels were strongly associated with all of the microRNAs studied [137]. In a prospective study, elevated baseline plasma miR-197-5P levels were considered to be associated with myocardial fibrosis in patients with end-stage HF, and during the average 937-day follow-up period, 22 patients $(27.5 \%)$ had major adverse cardiac events, including 19 deaths and three cardiac transplantations [138]. Additionally, multiple studies have found evidence implicating cardiac interstitial fibrosis in the deterioration of cardiac function in myocardial infarction. In AMI, miR-208 and miR-499 mediate cardioblastcardiomyocyte transformation and fast/slow muscle fiber specification at the late cardiogenic stages [139]. In addition, 4 weeks after coronary artery ligation in rats, miR-101 and miR-150 were decreased in the peri-infarct area and were expressed in cardiac fibroblasts [140, 141]. Moreover, miR-144 knockout mice demonstrated impaired late remodeling after MI, which was reflected by elevated total cardiac collagen content [142]. Interestingly, intermittent aerobic exercise could enhance the expression of cardiac miR-101a in rats with MI, and miR-101a was associated with decreased expression of fibrotic genes, such as Tgfb, fos, Smad2/3, CollAl, and Col3A1 [143]. These findings indicate that cardiac miRNAs (miR-208, miR-101, miR-150, and miR-144) play a central role in fibrosis after MI. Overall, miRNAs may become a potential therapeutic target for myocardial fibrosis (miRNAs are briefly summarized in Table 2).

\section{Conclusion}

Myocardial fibrosis, as a main component of most cardiovascular diseases, has been a major focus in recent years. Endomyocardial biopsy, which is the gold standard for the diagnosis of myocardial fibrosis, has limitations in terms of clinical application, whereas biomarkers seem to be easier and safer in terms of diagnosis, therapeutic monitoring, and prognosis. With the development of technology, the investigation of myocardial fibrosis biomarkers has received attention in clinical and research communities. A systematic review of biomarkers and pathological effects of myocardial fibrosis is presented in Fig. 2.

When selecting biomarkers in experiments, researchers should consider the purpose and method of the experiment. Some biomarkers are very likely "bystander" markers, but many are functional factors that are closely related to collagen synthesis and degradation. Specifically, PICP, PINP, and PIIINP are suitable representatives of the mechanism of collagen synthesis in target organ injury in myocardial fibrosis. CITP, MMPs, and TIMPs reflect collagen degradation, and the balance of collagen synthesis and degradation in turn indicates the stability of organ fibrosis. Therefore, PICP, PINP, PIIINP, CITP, MMPs, and TIMPs are functional factors that can directly reflect the degree of fibrosis. Moreover, in the process of fibrosis, collagen metabolism is affected by many molecules, such as TGF- $\beta$, Smads, CTGF, corin, mesenchymal cell products, and inflammatory factors. CTGF induces proliferation of fibroblasts and increases extracellular matrix content. Corin affects heart function by regulating natriuretic peptides. Inflammation always accompanies fibrosis, and hence inflammatory markers can reflect the relationship between them. EndoMT is one of the important sources of fibroblasts, and TGF- $\beta$, Smads, and miRNA are the main regulators of collagen gene expression. Therefore, TGF- $\beta$, Smads, CTGF, corin, mesenchymal cell products, and inflammatory factors are "bystander" markers that can indirectly affect the fibrosis process.

It is important to note that fibrosis occurs not only in the heart, but also in other organs, so that changes in biomarker levels may not have only a cardiac origin [25]. In another respect, biomarkers must be strictly tested to determine whether they strongly reflect myocardial fibrosis. Endomyocardial biopsy can be used to estimate the usefulness and accuracy of biomarkers. Only when these initiatives are successful can biomarkers be incorporated into clinical practice. Additionally, costeffectivity issues should also be taken into consideration, as the measurement of many biomarkers mentioned is not cheap, particularly when using a multiple-biomarker approach. Moreover, there is not currently a well-tested 
biomarker for fibrosis that is equivalent to NT-proBNP for HF. On the whole, the use of biomarkers is helpful in the assessment of myocardial fibrosis; therefore, more prospective studies are needed in the future.

\section{Acknowledgements}

This work was supported by the National Natural Science Foundation of China (No. 81904118 and 81603559) and Young Elite Scientists Sponsorship Program by CAST (No. CACM-2018-QNRC2-B04).

\section{Conflicts of Interest}

All authors declare no conflicts of interest.

\section{References}

[1] Berk BC, Fujiwara K, Lehoux S (2007). ECM remodeling in hypertensive heart disease. J Clin Invest, 117:568-575.

[2] Weber KT, Janicki JS, Shroff SG, Pick R, Chen RM, Bashey RI (1988). Collagen remodeling of the pressureoverloaded, hypertrophied nonhuman primate myocardium. Circ Res, 62:757-765.

[3] Medugorac I, Jacob R (1983). Characterisation of left ventricular collagen in the rat. Cardiovasc Res, 17:1521.

[4] Eghbali M, Czaja MJ, Zeydel M, Weiner FR, Zern MA, Seifter S, et al. (1988). Collagen chain mRNAs in isolated heart cells from young and adult rats. J Mol Cell Cardiol, 20:267-276.

[5] Eghbali M, Blumenfeld OO, Seifter S, Buttrick PM, Leinwand LA, Robinson TF, et al. (1989). Localization of types I, III and IV collagen mRNAs in rat heart cells by in situ hybridization. J Mol Cell Cardiol, 21:103-113.

[6] Engvall E, Hessle H, Klier G (1986). Molecular assembly, secretion, and matrix deposition of type VI collagen. J Cell Biol, 102:703-710.

[7] Caulfield JB, Janicki JS (1997). Structure and function of myocardial fibrillar collagen. Technol Health Care, 5:95-113.

[8] Rodriguez-Pascual F, Slatter DA (2016). Collagen cross-linking: insights on the evolution of metazoan extracellular matrix. Sci Rep, 6:37374.

[9] Querejeta R, López B, González A, Sánchez E, Larman M, Martínez Ubago JL, et al. (2004). Increased collagen type I synthesis in patients with heart failure of hypertensive origin: relation to myocardial fibrosis. Circulation, 110:1263-1268.

[10] Yang C, Qiao S, Song Y, Liu Y, Tang Y, Deng L, et al. (2019). Procollagen type I carboxy-terminal propeptide (PICP) and MMP-2 are potential biomarkers of myocardial fibrosis in patients with hypertrophic cardiomyopathy. Cardiovasc Pathol, 43:107150.

[11] Ferreira JP, Rossignol P, Pizard A, Machu JL, Collier T, Girerd N, et al. (2019). Potential spironolactone effects on collagen metabolism biomarkers in patients with uncontrolled blood pressure. Heart, 105:307-314.

[12] Adamcova M, Baka T, Dolezelova E, Aziriova S, Krajcirovicova K, Karesova I, et al. (2019). Relations between markers of cardiac remodelling and left ventricular collagen in an isoproterenol-induced heart damage model. J Physiol Pharmacol, 70: 1.

[13] Ruiz-Ruiz FJ, Ruiz-Laiglesia FJ, Samperiz-Legarre P, Lasierra-Diaz P, Flamarique-Pascual A, Morales-Rull JL, et al. (2007). Propeptide of procollagen type I (PIP) and outcomes in decompensated heart failure. Eur $\mathbf{J}$ Intern Med, 18:129-134.

[14] Weber KT, Sun Y, Guarda E, Katwa LC, Ratajska A, Cleutjens JP, et al. (1995). Myocardial fibrosis in hypertensive heart disease: an overview of potential regulatory mechanisms. Eur Heart J, 16: 24-28.

[15] Melkko J, Niemi S, Risteli L, Risteli J (1990). Radioimmunoassay of the carboxyterminal propeptide of human type I procollagen. Clin Chem, 36:1328-1332. [16] Colige A, Vandenberghe I, Thiry M, Lambert CA, Van Beeumen J, Li SW, et al. (2002). Cloning and characterization of ADAMTS-14, a novel ADAMTS displaying high homology with ADAMTS-2 and ADAMTS-3. J Biol Chem, 277:5756-5766.

[17] Risteli J, Risteli L (1995). Analysing connective tissue metabolites in human serum. Biochemical, physiological and methodological aspects. J Hepatol, 22:77-81.

[18] Zile MR, O'Meara E, Claggett B, Prescott MF, Solomon SD, Swedberg K, et al. (2019). Effects of Sacubitril/Valsartan on Biomarkers of Extracellular Matrix Regulation in Patients With HFrEF. J Am Coll Cardiol, 73:795-806.

[19] Zhang B, Li X, Chen C, Jiang W, Lu D, Liu Q, et al. (2018). Renal Denervation Effects on Myocardial Fibrosis and Ventricular Arrhythmias in Rats with Ischemic Cardiomyopathy. Cell Physiol Biochem, 46:2471-2479.

[20] Lombardi R, Betocchi S, Losi MA, Tocchetti CG, Aversa M, Miranda M, et al. (2003). Myocardial collagen turnover in hypertrophic cardiomyopathy. Circulation, 108:1455-1460.

[21] Linehan KA, Seymour AM, Williams PE (2001). Semiquantitative analysis of collagen types in the hypertrophied left ventricle. J Anat, 198:83-92.

[22] Brower GL, Gardner JD, Forman MF, Murray DB, Voloshenyuk T, Levick SP, et al. (2006). The relationship between myocardial extracellular matrix remodeling and ventricular function. Eur $\mathrm{J}$ Cardiothorac Surg, 30:604-610.

[23] Gelse K, Pöschl E, Aigner T (2003). Collagens-structure, function, and biosynthesis. Drug Deliv Rev, 55:1531-1546.

[24] Guha N, Erotokritou-Mulligan I, Bartlett C, Cowan DA, Bassett EE, Stow M, et al. (2012). The effects of a freeze-thaw cycle and pre-analytical storage temperature on the stability of insulin-like growth factor-I and pro-collagen type III N-terminal propeptide concentrations: Implications for the detection of growth hormone misuse in athletes. Drug Test Anal, 4:455-459. [25] Klappacher G, Franzen P, Haab D, Mehrabi M, Binder 
M, Plesch K, et al. (1995). Measuring extracellular matrix turnover in the serum of patients with idiopathic or ischemic dilated cardiomyopathy and impact on diagnosis and prognosis. T Am J Cardiol, 75:913-918.

[26] Lin YT, Lin YH, Wu XM, Ko CL, Yen RF, Chen YH, et al. (2017). The relationship between serum fibrosis markers and restrictive ventricular filling in patients with heart failure with reduced ejection fraction: A technetium-99m radionuclide ventriculography study. Oncotarget, 8:2381-2390.

[27] Yamazawa H, Murakami T, Takeda A, Takei K, Furukawa T, Nakajima H (2015). Serum concentration of procollagen type III amino-terminal peptide is increased in patients with successfully repaired coarctation of the aorta with left ventricular hypertrophy Pediatr Cardiol, 36:555-560.

[28] dos Santos Moreira C, Serejo F, Alcântara P, Ramalhinho V, Braz Nogueira J (2015). Procollagen type III amino terminal peptide and myocardial fibrosis: A study in hypertensive patients with and without left ventricular hypertrophy. Rev Port Cardiol, 34:309-314.

[29] Wu DM, Wang YJ, Han XR, Wen X, Li L, Xu L, et al. (2018). Tanshinone IIA prevents left ventricular remodelling via the TLR4/MyD88/NF- $\kappa \mathrm{B}$ signalling pathway in rats with myocardial infarction. J Cell Mol Med, 22:3058-3072.

[30] Laurent GJ (1987). Dynamic state of collagen: pathways of collagen degradation in vivo and their possible role in regulation of collagen mass. Am $\mathrm{J}$ Physiol, 252:C1-9.

[31] Risteli J, Elomaa I, Niemi S, Novamo A, Risteli L (1993). Radioimmunoassay for the pyridinoline crosslinked carboxy-terminal telopeptide of type I collagen: A new serum marker of bone collagen degradation. Clin Chem, 39:635-640.

[32] Morine KJ, Paruchuri V, Qiao X, Mohammad N, Mcgraw A, Yunis A, et al. (2016). Circulating multimarker profile of patients with symptomatic heart failure supports enhanced fibrotic degradation and decreased angiogenesis. Biomarkers, 21:91-97.

[33] Kallergis EM, Manios EG, Kanoupakis EM, Mavrakis HE, Arfanakis DA, Maliaraki NE, et al. (2008). Extracellular matrix alterations in patients with paroxysmal and persistent atrial fibrillation: biochemical assessment of collagen type-I turnover. J Am Coll Cardiol, 52:211-215.

[34] Nagao K, Inada T, Tamura A, Kajitani K, Shimamura K, Yukawa H, et al. (2018). Circulating markers of collagen types I, III, and IV in patients with dilated cardiomyopathy: relationships with myocardial collagen expression. ESC heart failure, 5:1044-1051.

[35] Manhenke C, Orn S, Squire I, Radauceanu A, Alla F, Zannad F, et al. (2011). The prognostic value of circulating markers of collagen turnover after acute myocardial infarction. Int J Cardiol, 150:277-282.

[36] Kitahara T, Takeishi Y, Arimoto T, Niizeki T, Koyama Y, Sasaki T, et al. (2007). Serum carboxy-terminal telopeptide of type I collagen (ICTP) predicts cardiac events in chronic heart failure patients with preserved left ventricular systolic function. Circ J, 71:929-935.
[37] Nagase H, Visse R, Murphy G (2006). Structure and function of matrix metalloproteinases and TIMPs. Cardiovasc Res, 69:562-573.

[38] Lindsay MM, Maxwell P, Dunn FG (2002). TIMP-1: a marker of left ventricular diastolic dysfunction and fibrosis in hypertension. Hypertension, 40:136-141.

[39] Cui N, Hu M, Khalil RA (2017). Biochemical and Biological Attributes of Matrix Metalloproteinases. Prog Mol Biol Transl Sci, 147:1-73.

[40] Hasty KA, Jeffrey JJ, Hibbs MS, Welgus HG (1987). The collagen substrate specificity of human neutrophil collagenase. J Biol Chem, 262:10048-10052.

[41] Knäuper V, López-Otin C, Smith B, Knight G, Murphy $G$ (1996). Biochemical characterization of human collagenase-3. J Biol Chem, 271:1544-1550.

[42] Konttinen YT, Ceponis A, Takagi M, Ainola M, Sorsa T, Sutinen M, et al. (1998). New collagenolytic enzymes/cascade identified at the pannus-hard tissue junction in rheumatoid arthritis: destruction from above. Matrix Biol, 17:585-601.

[43] Bigg HF, Rowan AD, Barker MD, Cawston TE (2007). Activity of matrix metalloproteinase-9 against native collagen types I and III. FEBS J, 274:1246-1255.

[44] Münch J, Avanesov M, Bannas P, Säring D, Krämer E, Mearini G, et al. (2016). Serum Matrix Metalloproteinases as Quantitative Biomarkers for Myocardial Fibrosis and Sudden Cardiac Death Risk Stratification in Patients With Hypertrophic Cardiomyopathy. J Card Fail, 22:845-850.

[45] Martos R, Baugh J, Ledwidge M, O'Loughlin C, Conlon C, Patle A, et al. (2007). Diastolic heart failure: evidence of increased myocardial collagen turnover linked to diastolic dysfunction. Circulation, 115:888895.

[46] González A, López B, Querejeta R, Zubillaga E, Echeverría T, Díez J (2010). Filling pressures and collagen metabolism in hypertensive patients with heart failure and normal ejection fraction. Hypertension, 55:1418-1424.

[47] Xiao T, Zeng O, Luo J, Wu Z, Li F, Yang J (2015). Effects of hydrogen sulfide on myocardial fibrosis in diabetic rats: Changes in matrix metalloproteinases parameters. Biomed Mater Eng, 26:S2033-2039.

[48] Arpino V, Brock M, Gill SE (2015). The role of TIMPs in regulation of extracellular matrix proteolysis. Matrix Biol, 115:247-254.

[49] Lovelock JD, Baker AH, Gao F, Dong JF, Bergeron AL, McPheat W, et al. (2005). Heterogeneous effects of tissue inhibitors of matrix metalloproteinases on cardiac fibroblasts. Am J Physiol Heart Circ Physiol, 288:H461-468

[50] Denhardt DT, Feng B, Edwards DR, Cocuzzi ET, Malyankar UM (1993). Tissue inhibitor of metalloproteinases (TIMP, aka EPA): structure, control of expression and biological functions. Pharmacol Ther, 59:329-341.

[51] Kwon JS, Kim YS, Cho AS, Cho HH, Kim JS, Hong $\mathrm{MH}$, et al. (2014). Regulation of MMP/TIMP by HUVEC transplantation attenuates ventricular remodeling in response to myocardial infarction. Life 
Sci, 101:15-26.

[52] Takawale A, Zhang P, Patel VB, Wang X, Oudit G, Kassiri Z (2017). Tissue Inhibitor of Matrix Metalloproteinase-1 Promotes Myocardial Fibrosis by Mediating CD63-Integrin $\beta 1$ Interaction. Hypertension, 69:1092-1103.

[53] Kawahara R, Niwa Y, Simizu S (2018). Integrin $\beta 1$ is an essential factor in vasculogenic mimicry of human cancer cells. Cancer Sci, 109:2490-2496.

[54] Espinosa-Carrasco G, Le Saout C, Fontanaud P, Michau A, Mollard P, Hernandez J, et al. (2018). Integrin $\beta 1$ Optimizes Diabetogenic T Cell Migration and Function in the Pancreas. Front Immunol, 9:1156.

[55] Hakanpaa L, Sipila T, Leppanen VM, Gautam P, Nurmi H, Jacquemet G, et al. (2015). Endothelial destabilization by angiopoietin-2 via integrin $\beta 1$ activation. Nat Commun, 6:5962.

[56] Yu C, Wang W, Jin X (2018). Hirudin Protects Ang IIInduced Myocardial Fibroblasts Fibrosis by Inhibiting the Extracellular Signal-Regulated Kinase1/2 (ERK1/2) Pathway. Med Sci Monit, 24:6264-6272.

[57] Westermann D, Heymans S (2014). Fibrosis or hypertrophy: let TIMPs decide. Cardiovasc Res, 103:196-197.

[58] Rizzi E, Ceron CS, Guimaraes DA, Prado CM, Rossi MA, Gerlach RF, et al. (2013). Temporal changes in cardiac matrix metalloproteinase activity, oxidative stress, and TGF- $\beta$ in renovascular hypertensioninduced cardiac hypertrophy. Exp Mol Pathol, 94:1-9.

[59] Parkkonen O, Nieminen MT, Vesterinen P, Tervahartiala T, Perola M, Salomaa V, et al. (2017). Low MMP-8/TIMP-1 reflects left ventricle impairment in takotsubo cardiomyopathy and high TIMP-1 may help to differentiate it from acute coronary syndrome. PLoS One, 12:e0173371.

[60] Frantz S, Störk S, Michels K, Eigenthaler M, Ertl G, Bauersachs J, et al. (2008). Tissue inhibitor of metalloproteinases levels in patients with chronic heart failure: an independent predictor of mortality. Eur $\mathrm{J}$ Heart Fail, 10:388-395.

[61] Travers JG, Kamal FA, Robbins J, Yutzey KE, Blaxall BC (2016). Cardiac Fibrosis: The Fibroblast Awakens. Circ Res, 118:1021-1040.

[62] Działo E, Tkacz K, Błyszczuk P (2018). Crosstalk between the TGF- $\beta$ and WNT signalling pathways during cardiac fibrogenesis. Acta Biochim Pol, 65:341349.

[63] Voloshenyuk TG, Landesman ES, Khoutorova E, Hart $\mathrm{AD}$, Gardner JD (2011). Induction of cardiac fibroblast lysyl oxidase by TGF- $\beta 1$ requires PI3K/Akt, Smad3, and MAPK signaling. Cytokine, 55:90-97.

[64] Bujak M, Frangogiannis NG (2007). The role of TGFbeta signaling in myocardial infarction and cardiac remodeling. Cardiovasc Res, 74:184-195.

[65] Davis J, Molkentin JD (2014). Myofibroblasts: trust your heart and let fate decide. J Mol Cell Cardiol, 70:918.

[66] Frantz S, Hu K, Adamek A, Wolf J, Sallam A, Maier SK, et al. (2008). Transforming growth factor beta inhibition increases mortality and left ventricular dilatation after myocardial infarction. Basic Res Cardiol, 103:485-492.

[67] Kuwahara F, Kai H, Tokuda K, Kai M, Takeshita A, Egashira K, et al. (2002). Transforming growth factorbeta function blocking prevents myocardial fibrosis and diastolic dysfunction in pressure-overloaded rats. Circulation, 106:130-135.

[68] Koitabashi N, Danner T, Zaiman AL, Pinto YM, Rowell J, Mankowski J, et al. (2011). Pivotal role of cardiomyocyte TGF- $\beta$ signaling in the murine pathological response to sustained pressure overload. J Clin Invest, 121:2301-2312.

[69] Liu L, Wang Y, Yan R, Li S, Shi M, Xiao Y, et al. (2016). Oxymatrine Inhibits Renal Tubular EMT Induced by High Glucose via Upregulation of SnoN and Inhibition of TGF- $\beta 1 /$ Smad Signaling Pathway. PLoS One, 11:e0151986.

[70] Pang L, Li Q, Wei C, Zou H, Li S, Cao W, et al. (2014). TGF- $\beta 1 /$ Smad signaling pathway regulates epithelialto-mesenchymal transition in esophageal squamous cell carcinoma: in vitro and clinical analyses of cell lines and nomadic Kazakh patients from northwest Xinjiang, China. PLoS One, 9:e112300.

[71] Xue K, Zhang J, Li C, Li J, Wang C, Zhang Q, et al. (2019). The role and mechanism of transforming growth factor beta 3 in human myocardial infarctioninduced myocardial fibrosis. J Cell Mol Med, 23:42294243.

[72] Khalil H, Kanisicak O, Prasad V, Correll RN, Fu X, Schips T, et al. (2017). Fibroblast-specific TGF- $\beta$ Smad2/3 signaling underlies cardiac fibrosis. J Clin Invest, 127:3770-3783.

[73] Bujak M, Ren G, Kweon HJ, Dobaczewski M, Reddy A, Taffet G, et al. (2007). Essential role of Smad3 in infarct healing and in the pathogenesis of cardiac remodeling. Circulation, 116:2127-2138.

[74] Bork P (1993). The modular architecture of a new family of growth regulators related to connective tissue growth factor. FEBS Lett, 327:125-130.

[75] Shi-Wen X, Leask A, Abraham D (2008). Regulation and function of connective tissue growth factor/CCN2 in tissue repair, scarring and fibrosis. Cytokine Growth Factor Rev, 19:133-144.

[76] Daniels JT, Schultz GS, Blalock TD, Garrett Q, Grotendorst GR, Dean NM, et al. (2003). Mediation of transforming growth factor-beta(1)-stimulated matrix contraction by fibroblasts: a role for connective tissue growth factor in contractile scarring. Am J Pathol, 163:2043-2052.

[77] Grotendorst GR, Rahmanie H, Duncan MR (2004). Combinatorial signaling pathways determine fibroblast proliferation and myofibroblast differentiation. FASEB J, 18:469-479.

[78] Frazier K, Williams S, Kothapalli D, Klapper H, Grotendorst GR (1996). Stimulation of fibroblast cell growth, matrix production, and granulation tissue formation by connective tissue growth factor. J Invest Dermatol, 107:404-411.

[79] Blom IE, Goldschmeding R, Leask A (2002). Gene regulation of connective tissue growth factor: new 
targets for antifibrotic therapy? Matrix Biol, 21:473482.

[80] Abreu JG, Ketpura NI, Reversade B, De Robertis EM (2002). Connective-tissue growth factor (CTGF) modulates cell signalling by BMP and TGF-beta. Nat Cell Biol, 4:599-604.

[81] Hong L, Lai HL, Fang Y, Tao Y, Qiu Y (2018). Silencing $\mathrm{CTGF} / \mathrm{CCN} 2$ inactivates the MAPK signaling pathway to alleviate myocardial fibrosis and left ventricular hypertrophy in rats with dilated cardiomyopathy. J Cell Biochem, 119:9519-9531.

[82] Nuamnaichati N, Sato VH, Moongkarndi P, Parichatikanond W, Mangmool S (2018). Sustained $\beta$ AR stimulation induces synthesis and secretion of growth factors in cardiac myocytes that affect on cardiac fibroblast activation. Life Sci, 193:257-269.

[83] Dean RG, Balding LC, Candido R, Burns WC, Cao Z, Twigg SM, et al. (2005). Connective tissue growth factor and cardiac fibrosis after myocardial infarction. $\mathrm{J}$ Histochem Cytochem, 53:1245-1256.

[84] Koitabashi N, Arai M, Niwano K, Watanabe A, Endoh M, Suguta M, et al. (2008). Plasma connective tissue growth factor is a novel potential biomarker of cardiac dysfunction in patients with chronic heart failure. Eur $\mathbf{J}$ Heart Fail, 10:373-379.

[85] Dong N, Chen S, Yang J, He L, Liu P, Zheng D, et al. (2010). Plasma soluble corin in patients with heart failure. Circ Heart Fail, 3:207-211.

[86] Yan W, Wu F, Morser J, Wu Q (2000). Corin, a transmembrane cardiac serine protease, acts as a proatrial natriuretic peptide-converting enzyme. Proc Natl Acad Sci U S A, 97:8525-8529.

[87] Potter LR, Abbey-Hosch S, Dickey DM (2006). Natriuretic peptides, their receptors, and cyclic guanosine monophosphate-dependent signaling functions. Endocr Rev, 27:47-72.

[88] Gladysheva IP, Wang D, McNamee RA, Houng AK, Mohamad AA, Fan TM, et al. (2013). Corin overexpression improves cardiac function, heart failure, and survival in mice with dilated cardiomyopathy. Hypertension, 61:327-332.

[89] Ichiki T, Boerrigter G, Huntley BK, Sangaralingham SJ, McKie PM, Harty GJ, et al. (2013). Differential expression of the pro-natriuretic peptide convertases corin and furin in experimental heart failure and atrial fibrosis. Am J Physiol Regul Integr Comp Physiol, 304:R102-109.

[90] Tran KL, Lu X, Lei M, Feng Q, Wu Q (2004). Upregulation of corin gene expression in hypertrophic cardiomyocytes and failing myocardium. Am J Physiol Heart Circ Physiol, 287:H1625-1631.

[91] Piera-Velazquez S, Li Z, Jimenez SA (2011). Role of endothelial-mesenchymal transition (EndoMT) in the pathogenesis of fibrotic disorders. Am J Pathol, 179:1074-1080.

[92] Koga M, Kuramochi M, Karim MR, Izawa T, Kuwamura M, Yamate J (2019). Immunohistochemical characterization of myofibroblasts appearing in isoproterenol-induced rat myocardial fibrosis. J Vet Med Sci, 81:127-133.
[93] 93. Geng H, Guan J (2017). MiR-18a-5p inhibits endothelial-mesenchymal transition and cardiac fibrosis through the Notch2 pathway. Biochem Biophys Res Commun, 491:329-336.

[94] Challa AA, Vukmirovic M, Blackmon J, Stefanovic B (2012). Withaferin-A reduces type I collagen expression in vitro and inhibits development of myocardial fibrosis in vivo. PLoS One, 7:e42989.

[95] Yu L, Ruifrok WP, Meissner M, Bos EM, van Goor H, Sanjabi B, et al. (2013). Genetic and pharmacological inhibition of galectin-3 prevents cardiac remodeling by interfering with myocardial fibrogenesis. Circ Heart Fail, 6:107-117.

[96] Lubrano V, Balzan S (2020). Role of oxidative stressrelated biomarkers in heart failure: galectin $3, \alpha 1-$ antitrypsin and LOX-1: new therapeutic perspective? Mol Cell Biochem, 464:143-152.

[97] Fang L, Ellims AH, Beale AL, Taylor AJ, Murphy A, Dart AM (2017). Systemic inflammation is associated with myocardial fibrosis, diastolic dysfunction, and cardiac hypertrophy in patients with hypertrophic cardiomyopathy. Am J Transl Res, 9:5063-5073.

[98] de Boer RA, Voors AA, Muntendam P, van Gilst WH, van Veldhuisen DJ (2009). Galectin-3: a novel mediator of heart failure development and progression. Eur $\mathrm{J}$ Heart Fail, 11:811-817.

[99] Liu X, Gu Y, Liu Y, Zhang M, Wang Y, Hu L (2018). Ticagrelor attenuates myocardial ischaemia-reperfusion injury possibly through downregulating galectin-3 expression in the infarct area of rats. $\mathrm{Br} \mathrm{J} \mathrm{Clin}$ Pharmacol, 84:1180-1186.

[100] Vergaro G, Del Franco A, Giannoni A, Prontera C, Ripoli A, Barison A, et al. (2015). Galectin-3 and myocardial fibrosis in nonischemic dilated cardiomyopathy. Int J Cardiol, 184:96-100.

[101] Shen H, Wang J, Min J, Xi W, Gao Y, Yin L, et al. (2018). Activation of TGF- $\beta 1 / \alpha-S M A / C o l$ I Profibrotic Pathway in Fibroblasts by Galectin-3 Contributes to Atrial Fibrosis in Experimental Models and Patients. Cell Physiol Biochem, 47:851-863.

[102] Nguyen MN, Su Y, Vizi D, Fang L, Ellims AH, Zhao WB, et al. (2018). Mechanisms responsible for increased circulating levels of galectin-3 in cardiomyopathy and heart failure. Sci Rep, 8:8213.

[103] Bivona G, Bellia C, Lo Sasso B, Agnello L, Scazzone C, Novo G, et al. (2016). Short-term Changes in Gal 3 Circulating Levels After Acute Myocardial Infarction. Arch Med Res, 47:521-525.

[104] van Kimmenade RR, Januzzi JL, Ellinor PT, Sharma UC, Bakker JA, Low AF, et al. (2006). Utility of aminoterminal pro-brain natriuretic peptide, galectin-3, and apelin for the evaluation of patients with acute heart failure. J Am Coll Cardiol, 48:1217-1224.

[105] Maiolino G, Rossitto G, Pedon L, Cesari M, Frigo AC, Azzolini M, et al. (2015). Galectin-3 predicts long-term cardiovascular death in high-risk patients with coronary artery disease. Arterioscler Thromb Vasc Biol, 35:725732 .

[106] Wynn TA, Barron L (2010). Macrophages: master regulators of inflammation and fibrosis. Semin Liver 
Dis, 30:245-257.

[107] 107. Kong P, Christia P, Frangogiannis NG (2014). The pathogenesis of cardiac fibrosis. Cell Mol Life Sci, 71:549-574.

[108] Kang P, Wang J, Fang D, Fang T, Yu Y, Zhang W, et al. (2020). Activation of ALDH2 attenuates high glucose induced rat cardiomyocyte fibrosis and necroptosis. Free Radic Biol Med, 146:198-210.

[109] Schafer S, Viswanathan S, Widjaja AA, Lim WW, Moreno-Moral A, DeLaughter DM, et al. (2017). IL-11 is a crucial determinant of cardiovascular fibrosis. Nature, 552:110-115.

[110] Morrison J, Lu QL, Pastoret C, Partridge T, BouGharios G (2000). T-cell-dependent fibrosis in the $\mathrm{mdx}$ dystrophic mouse. Lab Invest, 80:881-891.

[111] Dehne N, Kerkweg U, Flohé SB, Brüne B, Fandrey J (2011). Activation of hypoxia-inducible factor 1 in skeletal muscle cells after exposure to damaged muscle cell debris. Shock, 35:632-638.

[112] O'Connell RM, Taganov KD, Boldin MP, Cheng G, Baltimore D (2007). MicroRNA-155 is induced during the macrophage inflammatory response. Proc Natl Acad Sci U S A, 104:1604-1609.

[113] Das A, Ganesh K, Khanna S, Sen CK, Roy S (2014). Engulfment of apoptotic cells by macrophages: a role of microRNA-21 in the resolution of wound inflammation. J Immunol, 192:1120-1129.

[114] Hsu SY, Nakabayashi K, Nishi S, Kumagai J, Kudo M, Sherwood OD, et al. (2002). Activation of orphan receptors by the hormone relaxin. Science, 295:671-674

[115] Simon J, Nemeth E, Nemes A, Husveth-Toth M, Radovits T, Foldes G, et al. (2019). Circulating Relaxin1 Level Is a Surrogate Marker of Myocardial Fibrosis in HFrEF. Front Physiol, 10:690.

[116] Wang M, Qian L, Li J, Ming H, Fang L, Li Y, et al. (2019). GHSR Deficiency Exacerbates Cardiac Fibrosis: Role in Macrophage Inflammasome Activation and Myofibroblast Differentiation. Cardiovasc Res, in press.

[117] Li H, Zhou Y, Song W, Li J, Xu J (2019). Expression of ADAMTS-1 mRNA in myocardium of viral heart disease mice and its clinical significance. Exp Ther Med, 17:153-158.

[118] Zhou Y, Yi X, Wang T, Li M (2015). Effects of angiotensin II on transient receptor potential melastatin 7 channel function in cardiac fibroblasts. Exp Ther Med, 9:2008-2012

[119] Vickers KC, Rye KA, Tabet F (2014). MicroRNAs in the onset and development of cardiovascular disease. Clin Sci, 126:183-194.

[120] 120. Fang L, Ellims AH, Moore XL, White DA, Taylor AJ, Chin-Dusting J, et al. (2015). Circulating microRNAs as biomarkers for diffuse myocardial fibrosis in patients with hypertrophic cardiomyopathy. J Transl Med, 13:314.

[121] Villar AV, García R, Merino D, Llano M, Cobo M, Montalvo C, et al. (2013). Myocardial and circulating levels of microRNA-21 reflect left ventricular fibrosis in aortic stenosis patients. Int J Cardiol, 167:2875-2881.

[122] Zhou XL, Xu H, Liu ZB, Wu QC, Zhu RR, Liu JC (2018). miR-21 promotes cardiac fibroblast-to- myofibroblast transformation and myocardial fibrosis by targeting Jagged1. J Cell Mol Med, 22:3816-3824

[123] Gupta SK, Itagaki R, Zheng X, Batkai S, et al. MiR-21 promotes fibrosis in an acute cardiac allograft transplantation model. Cardiovasc Res, 110:215-226.

[124] Szemraj-Rogucka ZM, Szemraj J, Masiarek K, Majos A (2019). Circulating microRNAs as biomarkers for myocardial fibrosis in patients with left ventricular noncompaction cardiomyopathy. Arch Med Sci, 15:376384.

[125] Thum T (2014). Noncoding RNAs and myocardial fibrosis. Nat Rev Cardiol, 11:655-663.

[126] Heid J, Cencioni C, Ripa R, Baumgart M, Atlante S, Milano G, et al. (2017). Age-dependent increase of oxidative stress regulates microRNA-29 family preserving cardiac health. Sci Rep, 7:16839.

[127] Abonnenc M, Nabeebaccus AA, Mayr U, BarallobreBarreiro J, Dong X, Cuello F, et al. (2013). Extracellular matrix secretion by cardiac fibroblasts: role of microRNA-29b and microRNA-30c. Circ Res, 113:1138-1147.

[128] Sassi Y, Avramopoulos P, Ramanujam D, Grüter L, Werfel S, Giosele S, et al. (2017). Cardiac myocyte miR-29 promotes pathological remodeling of the heart by activating Wnt signaling. Nat Commun, 8:1614.

[129] Karakikes I, Chaanine AH, Kang S, Mukete BN, Jeong D, Zhang S, et al. (2013). Therapeutic cardiac-targeted delivery of miR-1 reverses pressure overload-induced cardiac hypertrophy and attenuates pathological remodeling. J Am Heart Assoc, 2:e00078.

[130] Yuan J, Liu H, Gao W, Zhang L, Ye Y, Yuan L, et al. (2018). MicroRNA-378 suppresses myocardial fibrosis through a paracrine mechanism at the early stage of cardiac hypertrophy following mechanical stress. Theranostics, 8:2565-2582.

[131] Yang X, Li X, Lin Q, Xu Q (2019). Up-regulation of microRNA-203 inhibits myocardial fibrosis and oxidative stress in mice with diabetic cardiomyopathy through the inhibition of PI3K/Akt signaling pathway via PIK3CA. Gene, 715:143995.

[132] Wei Y, Wu Y, Feng K, Zhao Y, Tao R, Xu H, et al. (2020). Astragaloside IV inhibits cardiac fibrosis via miR135a-TRPM7-TGF- $\beta$ /Smads pathway. J Ethnopharmacol, 249:112404.

[133] Beaumont J, López B, Hermida N, Schroen B, San José G, Heymans S, et al. (2014). microRNA-122 downregulation may play a role in severe myocardial fibrosis in human aortic stenosis through TGF- $\beta 1$ up-regulation. Clin Sci, 126:497-506.

[134] Xu Q, Lin XX, Liu P, Zhang W, Tang K, Zhai YS, et al. (2019). MiR-195 inhibits myocardial fibrosis in hypertensive rats by regulating TGF $\beta 1-S m a d 3$ signaling pathway. Eur Rev Med Pharmacol Sci, 23:8087-8094.

[135] Zhao D, Li C, Yan H, Li T, Qian M, Zheng N, et al. (2018). Cardiomyocyte Derived miR-328 Promotes Cardiac Fibrosis by Paracrinely Regulating Adjacent Fibroblasts. Cell Physiol Biochem, 46:1555-1565.

[136] Wu HY, Wu JL, Ni ZL (2019). Overexpression of microRNA-202-3p protects against myocardial 
ischemia-reperfusion injury through activation of TGF$\beta 1 /$ Smads signaling pathway by targeting TRPM6. Cell cycle, 18:621-637.

[137] Rubiś P, Totoń-Żurańska J, Wiśniowska-Śmiałek S, Holcman K, Kołton-Wróż M, Wołkow P, et al. (2017). Relations between circulating microRNAs (miR-21, miR-26, miR-29, miR-30 and miR-133a), extracellular matrix fibrosis and serum markers of fibrosis in dilated cardiomyopathy. Int J Cardiol, 231:201-206.

[138] Liu W, Zheng J, Dong J, Bai R, Song D, Ma X, et al. (2018). Association of miR-197-5p, a Circulating Biomarker for Heart Failure, with Myocardial Fibrosis and Adverse Cardiovascular Events among Patients with Stage C or D Heart Failure. Cardiology, 141:212225.

[139] Chistiakov DA, Orekhov AN, Bobryshev YV (2016). Cardiac-specific miRNA in cardiogenesis, heart function, and cardiac pathology (with focus on myocardial infarction). J Mol Cell Cardiol, 94:107-121.

[140] Pan Z, Sun X, Shan H, Wang N, Wang J, Ren J, et al.
(2012). MicroRNA-101 inhibited postinfarct cardiac fibrosis and improved left ventricular compliance via the FBJ osteosarcoma oncogene/transforming growth factor- $\beta 1$ pathway. Circulation, 126:840-850.

[141] Deng P, Chen L, Liu Z, Ye P, Wang S, Wu J, et al. (2016). MicroRNA-150 Inhibits the Activation of Cardiac Fibroblasts by Regulating c-Myb. Cell Physiol Biochem, 38:2103-2122.

[142] He Q, Wang F, Honda T, James J, Li J, Redington A (2018). Loss of miR-144 signaling interrupts extracellular matrix remodeling after myocardial infarction leading to worsened cardiac function. Sci Rep, 8:16886.

[143] Xiao L, He H, Ma L, Da M, Cheng S, Duan Y, et al. (2017). Effects of miR-29a and miR-101a Expression on Myocardial Interstitial Collagen Generation After Aerobic Exercise in Myocardial-infarcted Rats. Arch Med Res, 48:27-34. 